\title{
Economic Value of Cultural Development of Chinese Sports Tourism Research
}

\author{
Weiqi Jiang ${ }^{1}$, Ying Liu ${ }^{2}$, Qian Yang ${ }^{1}$, Bing Zhang, ${ }^{1}$ * \\ ${ }^{1}$ Institute of Physical Education, Huanggang Normal University, Huangzhou 438000, Hubei, China \\ ${ }^{2}$ Graduate School of Education, Shandong Sport University, Jinan 250102, Shandong, China
}

\begin{abstract}
With the rapid development of China's social economy, the sports tourism industry has made great development space. The construction and development of Chinese sports tourism culture in many ways to save the problem. Is studied in this paper, the methods of literature, the origin and development of sports tourism culture, analysis of the current situation of the development of Chinese sports tourism culture, expounds the development of sports tourism culture value, and put forward the problems existing in the development of sports tourism industry, and countermeasures put forward some Suggestions to promote the development of sports tourism industry. The results showed that the sports tourism has a strong openness, China is now in many parts of the sports tourism industry lack of effective marketing channels, its overall impact ability to ascend, this leads to lack of visibility and influence in these areas, the lack of market competitiveness, is difficult to obtain the effective development and progress. China must pay highly attention to this, to strengthen the construction of sports tourism culture, promote the development of sports tourism industry.
\end{abstract}

Keywords: Sports tourism; Sports culture; Economic value; Asian sports

\section{INTRODUCTION}

With the continuous development of social economy, the continuous increasing of human civilization has made great development in all walks of life, of which the progress of the transportation enterprise great impetus to the development of the tourism industry, sport is a series of reforms, people gradually clear the rules of the sports events, sports activities to enhance organization and discipline, in People's Daily life become the indispensable cultural activities, and with the increasing of sports, sports tourism culture has made great development space and good prospects for development [1-3]. In 2001 China theme of tourism in sports fitness activities, for example, when China to overseas tourists to provide large rich national characteristics of sports fitness activities to reach 60, has received the praise of Chinese and foreign tourists, and the culture of Chinese sports tourism has been rapid development [4,5]. However it is important to note that the China sports tourism culture industry are still many deficiencies in the process of development, compared with some developed countries, the development of Chinese sports tourism in the development of cultural industry scale, speed, workers and degree of tourism resource development gap is very obvious, therefore, in order to promote the development of sports tourism culture industry in China, we must vigorously development of sports tourism culture, to develop sports tourism and cultural tourism resources, in order to support the development of Chinese sports tourism culture [6]. In recent years, the scale of the sports tourism is more and more big, also more and more rich content, as a kind of spiritual product which make people's consumption got great development, people's consumption habits as the degree of change, the development of the sports tourism industry for people's physical and mental health and the growth of the national economy is more and more important significance and function [7].

\section{VAlue OF Sports Tourism Culture}

Sports tourism industry is not only economic industry, but also the cultural industry, the development of sports tourism to promote the development of relevant industries, encourage regional economic prosperity has a very positive meaning. Moreover, sports tourism can improve the attention of all countries in the region, as the number of tourist increases, will also get great economic development in western China, the region's popularity will be improved at the same time, and then make the sports tourism cities has great social influence. 
Sports tourism culture has enormous economic value, in addition to itself to its regional economic development has played a very positive influence, it can promote the employment, maintain social stability. In addition, physical culture and sports spirit will be with the development of sports tourism and widely spread, and to promote the international communication, to improve the international influence of China. Related to the survey, the global to the leisure entertainment, physical fitness for the purpose of tourism accounts for the largest proportion, therefore, China should be aimed at sports tourism to develop continuously, actively controlling the world tourism market share, to promote the spread of Chinese traditional sports culture and sports spirit, through the tourism industry to strengthen the communication between China and international, in promoting global economic and cultural exchanges at the same time, to effectively improve China's international influence [8].

Sports tourism culture to make people's body and mind, edify sentiment has a positive effect, can to promote spiritual civilization construction. Sports tourism will hone man's spirit will through sports activities, to improve people's aesthetic taste. Coupled with the beautiful natural landscape and social landscape, makes people to alleviate pressure, ease tension. With the rapid development of modern society, the role of sports tourism is more and more big, so we must pay highly attention to this, developing sports tourism industry, to promote the development of China's construction of spiritual civilization.

\section{Problems Existing in the Development of Chinese Sports Tourism Culture}

Although Chinese sports tourism has developed rapidly in recent years, however, compared with some developed countries, the sports tourism of China starts relatively late, weak development foundation, is still at a disadvantage position in many ways, with the development of sports tourism resources in various areas of asymmetry is very strong, in the economic development of the related survey, the existing problems in the development of sports tourism industry in China are mainly the following several aspects:

\subsection{Lack of Accessibility}

In rural areas and minority areas of sports tourism scenic transportation lack of smooth cohesion, difficult to form, the coordination of traffic resources development and utilization situation is not ideal. Some outdoor sports like mountaineering, exploration, drift is away from the traffic center, the sports tourism project related services difficulty is very high. Although China is rich in sports tourism resources, low labor costs, and then restricted to high transport costs, make the development of Chinese sports tourism culture is heavily influenced by the restrictions.

\subsection{Lack of Attractive and Competitive}

Parts of China lack of hierarchy, the development of sports tourism resources of many single project development, lack of sports tourism project with the regional characteristic, which makes the sports tourism is difficult to attract tourists to participate in these areas, lack of competitiveness and influence. Repeat some regional sports tourism construction, low level, at the same time also produced a large number of costs limit the choice of sports tourists, causing many of the tourists, who was not involved in sports tourism project will, have set back the development of sports tourism industry.

\subsection{Income Situation is Not Ideal}

Compared with other tourism projects, sports tourism consumption level is higher, only to reach a certain level of income has the ability to participate in sports tourism project, and after the income reached a certain level, its spending power will get improved with income growth. Yet some parts of China, especially in the central and western regions of population average income is relatively low, in which the number of people involved in sports tourism consumption is relatively small, and the consumption gap of people participating in sports tourism is also very big. Limited spending power, coupled with excessive sports tourism consumption, makes a serious shortage of sports tourism market demand.

\subsection{The Lack of Perfect Sports Tourism Infrastructure Construction}

At present China's sports tourism infrastructure construction and development level is not ideal, coupled with the lack of adequate funds, lead to many parts of the sports tourism infrastructure construction lag, difficult to follow up the development of the sports tourism activities, which limits 
the development of sports tourism industry. The survey also showed that the current Chinese sports tourists to China sports tourism infrastructure satisfaction degree is generally low, resulting in sports tourists growing demand is difficult to satisfy.

\subsection{Lack of Awareness of Sports Tourism}

At present, China's sports tourism is still in the stage of development, people's cognition of the sports tourism is not high, the lack of specific performance of its concept, function, and the deep understanding of the nature and experience. Related survey shows that most of China's population of sports tourism without a clear concept, also do not understand the role of sports tourism. An important reason lead to this phenomenon, is China's cultural level balance is missing, the lack of unified understanding, combined with the propaganda work does not reach the designated position, lead to people's awareness of the sports tourism is not high.

\subsection{Environmental Protection Work Does Not Reach the Designated Position}

With the rapid development of China's social economy, the urbanization process, in the process of the development of sports tourism resources with damage to the environment, the natural ecosystems have been difficult to load the effects of social and economic activities. In some areas there are serious ecological damage phenomenon, such as air again, vegetation destruction, soil erosion and so on, these areas are bad ecological environment difficult to achieve sustainable development, to the development of economic construction at the same time also caused serious influence. Due to the poor ecological environment, ecological environment destruction costs continue to increase, make the sports tourism development is limited by the great development of sports tourism.

\subsection{Lack of Marketing Channels, Lack of Professional Talent Team Construction}

As an export-oriented industry, sports tourism has a strong openness, therefore rely heavily on promotion. And at present the Chinese sports tourism industry in many parts of the lack of effective marketing channels, its overall impact ability to ascend, this leads to the popularity and influence of these areas is insufficient, lack of market competitiveness, is difficult to obtain the effective development and progress. At the same time, some areas of sports tourism marketing fund input are insufficient, the professional talent team construction does not reach the designated position, make relevant sports tourism management talent shortage, the level of the sports tourism research institutions is low, which restricts the development of sports tourism industry.

\section{Countermeasures to Promote the Development of Sports Tourism Culture}

In order to promote the construction and development of the tourism culture, we must build the concept of scientific development, strict implementation of the sustainable development strategy, in order to promote social and economic development. Has a comprehensive sports tourism industry, its development should adhere to the "people-oriented" concept, for different levels and the interests of all parties to do overall consideration, to ensure good social benefit, economic benefit and environmental benefit. In sports tourism development process, should from the aspects of strengthening its activity experience, to ensure the demand of sports tourist degree of satisfaction. Also, optimize the structure of sports tourism products, expand the scale of industry, improve the overall quality, realize the sustainable development of sports tourism.

Sports tourism industry should strengthen the brand construction, make with characteristic of regional brand, and create brand effect, increase social influence. In addition, people should enhance the cognition of sports tourism culture, to deep mining of the connotation of sports tourism, to develop the sports tourism project, change the current situation of sports tourism content single. From sports tourism various elements, improve the sports travel information service, improve the image of the sports tourism and enhance the competitiveness of the regional sports tourism and attractive.

Due to China's vast territory, different areas have different characteristics, so we must make overall planning, optimization of sports tourism resources integration, the integration of regional resources should be considered when the global development, cast off the yoke of the regionalism idea, realize the joint development, in order to promote the sustained, stable development of sports tourism industry. Because there exist certain disadvantages to the parts of transportation construction, which limits the development of sports tourism industry, therefore, must strengthen the construction of traffic in the area, improve traffic cohesion, to make clear on the area to improve. Should be according 
to the actual development condition and the foundation, based on the developed traffic network, prompted transportation infrastructure network structure to improve, to do a good job of coordination, make full use of transport resources, enhance the accessibility of sports tourism scenic spot.

In order to improve the participation of sports tourism and view and admire a gender, it is necessary to strengthen ecological environmental protection, in order to promote the construction and development of the sports tourism culture. Resolutely put an end to the expense of the ecological environment for the economic growth of sports tourism industry, should be to ensure economic growth at the same time, realize the harmony between man and nature, improve the appeal of sports tourism resources, set up the correct environmental protection idea, realize the sustainable development of sports tourism resources.

\section{CONCLuSION}

To sum up, the sports tourism culture construction and development for China's economic development has the extremely vital significance. However, at present the Chinese sports tourism industry in the development process there are still many deficiencies, compared with some developed countries there is still a big gap, these problems seriously restrict the development of sports tourism in China. Therefore, we must to solve these problems, intensive research, careful analysis the reasons of the problems, and put forward effective countermeasures, to strengthen the construction of sports tourism culture, promote the development of the sports tourism industry, to promote China's social and economic construction and development provide strong guarantee.

\section{REFERENCES}

[1] BAO Ming-xiao. Occupation Sports is the Core Capability of Sports Power[J]. Journal of Nanjing Institute of Physical Education, 2011, 25(5):4-6.

[2] DAI Guang-quan, YANG Li-juan. An Introduction to Sport Tourism and its Latest Research in West Countries [J]. Journal of Guilin Institute of Tourism, 2005, 16(1):68-74.

[3] Margaret Deery. Leo Jago, Liz Fredline. Sport Tourism or Event are they one the same [J]. Sport Tourism, 2004, 9(3):235-245.

[4] JIANG Fu-gao.A Philosophical Thought on the Concept of Sports Tourism [J].Journal of Capital College of Physical Education, 2005, 17(4):30-31.

[5] CHEN Hao, REN Yu-yong, WANG Li, LI Han-xu, QU Jin and SUN Shuang-ming. Sustainable Development of Ecological Sports Tourism: A Case Study of the Beijing-Hangzhou Grand Canal[J]. Journal of Beijing Sport University, 2015, 38(4):26-32.

[6] LI Gang, SUN Jin-hai and DAI Gang. An Empirical Study on Sports Tourism Risk Perceptual Consuming Behavior of Urban Residents [J]. Journal of Beijing Sport University, 2016, 39(6):20-28.

[7] LI Yuehua. The Research on the Integration of Green Ecotourism, Red Tourism and Patina Tourism Resources in Huanggang City[J].Ecological Economy, 2010,(2):109-111.

[8] WU Ling-min, QU Jin and LI Han-xu. Construction of China Regional Sports Tourism Ecosphere System [J]. Journal of Beijing Sport University, 2016, 39(7):30-36. 


\section{AUTHORS' BIOGRAPHY}

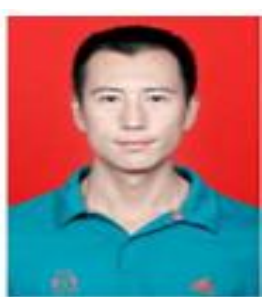

Weiqi Jiang (1983-) male, Korea, master graduate student, lecturer. Methods: social sports, the sports education.

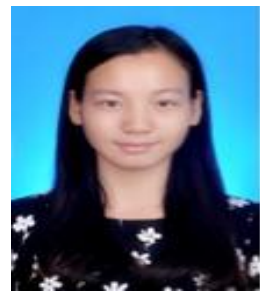

Ying Liu (1993- ), female, physical education postgraduate master, Wuhan Hubei, Shandong Sport University, the research direction: sports industry and physical fitness. Address: No.10600, Century Avenue, Jinan City, Shandong Provence, P.R. China (Shandong Sport University)

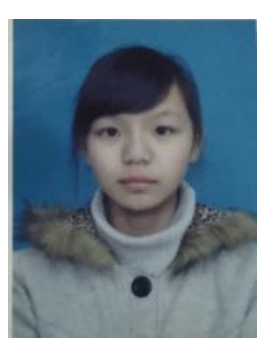

Qian Yang (1996-), female, the Han nationality, hubei wuhan, undergraduate degree, research assistant, Institute of Physical Education Huanggang Normal University grade 2014students; research interests: sports industry and sports engineering, sports management.

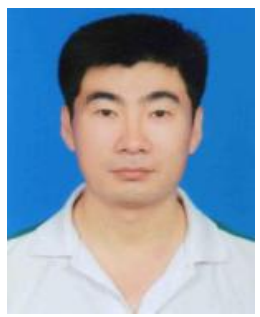

Bing Zhang (1973-), male, Mongolian, liaoning chaoyang, master degree, associate professor, research interests: sports industry and sports engineering, sports management. Address: No. 146, Xingang 2 Road, Huanggang City, Hubei Province, P.R.China (Institute of Physical Education, Huanggang Normal University 